\title{
Interaction between gene polymorphisms in MLL3 gene and TGF- $\beta$ signal pathway with the susceptibility of type $B$ aortic dissection in the Chinese population
}

qinghua Yuan

The Seventh Affiliated Hospital of Sun Yat-sen University

\section{Yafei Chang}

Zhongshan School of Medicine

\section{Peipei Jiang}

The Fourth People's Hospital of Urumqi City

\section{Ling Sun}

Fuyang Tumor hospital, Fuyang, China.

\section{Yitong Ma}

First Affiliated Hospital of Xinjiang Medical University

Xiang Ma ( $\sim$ maxiangxj@yeah.net )

First Affiliated Hospital of Xinjiang Medical University

\section{Research Article}

Keywords: MLL3, TGF $\beta$ polymorphisms; Type B AD

Posted Date: January 13th, 2022

DOI: https://doi.org/10.21203/rs.3.rs-1215325/v1

License: (c) (i) This work is licensed under a Creative Commons Attribution 4.0 International License.

Read Full License 


\section{Abstract}

Objective: To investigate the impact of MLL3 polymorphisms and Transforming growth factor- $\beta$ (TGF- $\beta$ ) pathway additional their interactions with type $B$ aortic dissection (AD) risk based on the Chinese population.

Methods: We investigated the MLL3 (rs10244604, rs6963460, rs1137721), TGF $\beta 1$ (rs1800469), TGF 32 (rs900), TGFR1 (rs1626340) and TGFR2 (rs4522809) gene polymorphisms analysis. Logistic regression was performed to investigate the association between 7 SNPs and Type B AD. GMDR software was used to analyze gene-gene and gene-environment interactions. Odds ratio (OR) with a $95 \%$ confidence interval (Cl) was employed to evaluate the association of genes and Type B AD risk.

Results: Genotypes and alleles distribution in case and control groups showed significant differences $(P<0.05)$. Logistic regression has shown that the Type B AD risk was the highest in those with rs1137721 CT genotype, $(\mathrm{OR}=4.33,95 \% \mathrm{Cl}=1.51-12.40)$. Meanwhile, WBC, Drinking, Hypertension, $\mathrm{TG}$, and LDL-C were independent risk factors for Type $B A D$. Respectively, Logistic regression showed that the Type $B A D$ risk was the highest in those with rs1137721-TT+CT and rs4522809-AA genotype (OR=6.72, 95\% $\mathrm{Cl}=1.56$ 29.84), and was lowest in those with rs1137721-CC and rs4522809-AA+GG genotype (OR=4.38, $95 \% \mathrm{Cl}=0.92-20.83)$. However, 55-month median long-term follow-up were not show significant.

Conclusion: MLL3 (rs1137721) with TGF $\beta 1$ (rs4522809) polymorphisms may be closely related to the development of Type B AD. Inflammation reaction and lipid metabolism were associated with the morbility of Type B AD. Moreover, there exist gene-gene interactions among these susceptibility genes. These may become new diagnostic and research goal for Type B AD.

\section{Introduction}

Type B Aortic dissection (AD) accompanied by significant morbidity and mortality ${ }^{[1]}$. AD develops through interactions among numerous factors, including genetics related mutations and environmental factors ${ }^{[3,4]}$; The complicated pathogenesis of $A D$ involved by the structural weakness of aortic connective tissue and increased TGF- $\beta$ signaling pathway ${ }^{[5-6]}$. Aortic media and adventitia are infiltrated by inflammatory $T$ lymphocytes and macrophages ${ }^{[7-8]}$, Some of which are epigenetic modifications ${ }^{[9-10]}$.

In the development and maintenance of vasculature transforming growth factor- $\beta$ (TGF- $\beta$ ) signaling plays a crucial role ${ }^{[11-12]}$. TGF- $\beta$ receptors TGFBR1 and TGFBR2 as the canonical TGF- $\beta$ signaling cascade in genes encoding mutations are commonly encountered ${ }^{[13]}$, their cognate ligands TGF- $\beta 2^{[14]}$, an intracellular effector of TGF- $\beta$ signaling ${ }^{[15]}$.

In many cardiovascular diseases, epigenetic significant modifications can affect disease development or progression. Lysine methyltransferase 2C (KMT2C, MII3), an H3K4 methyltransferase has participated in adipogenesis, and once mice with lethal mutations show reduced adiposity. MLL3 and MLL4 have distinct and critical roles in the regulation of transcription in lipid accumulation, and increased energy 
expenditure and bile acid (BA) levels ${ }^{[16-18]}$. However, the relationship between MLL3 polymorphisms and aortic dissection is not known. Understanding the biology of AD-related disorders remains insufficient. The study aimed to investigate the impact of MLL3 and TGF- $\beta$ signal pathway, and synergistic interaction between MLL3 and TGF- $\beta$ signal pathway on Type B AD risk.

\section{Methods}

\subsection{Ethics Statement}

The present study was approved by the Ethics Committee of the First Affiliated Hospital of Xinjiang Medical University and conducted according to the standards of the Declaration of Helsinki. Written informed consent was obtained from all participants. All patients underwent a physical examination and biochemical screening at baseline.

\subsection{Sample Design}

We recruited people who in hospital at the First Affiliated Hospital of Xinjiang Medical University from 2012 to 2016. All of them underwent Computed tomography angiography (CTA). We enrolled 382 participants (AD patients:175; Control groups:197). AD patients underwent interventional surgery. The control patients who performed Coronary angiography were proofed no coronary disease. The sex ratio of patients and the control group was 1:1. The age ranged from 20 to 86 years, with mean $\pm S D$ age of $53.78 \pm 11.91$ years (AD patients, $51.18 \pm 12.01$ years; Control groups: $55.87 \pm 11.43$ years). Demographic data information about the presence of traditional heart disease risk factors: including hypertension, smoking, alcohol consumption, and diabetes mellitus. Blood samples obtained for measurement of basal fasting serum concentrations of white blood cell, creatinine, total cholesterol, high-density lipoprotein cholesterol, low-density lipoprotein cholesterol, glucose, triglycerides, and fasting blood glucose (FBG) measured by the clinical laboratory department of the First Affiliated Hospital of Xinjiang Medical University with a biochemical analyzer (Dimension AR/AVL Clinical Chemistry System, Newark, NJ, USA). Left ventricular diastolic diameter (LVDd) and left ventricular systolic diameter (LVSd) were twodimensionally measured using Hp5500 the ultrasonocardiograph. Left ventricular ejection fraction (EF) was calculated based on the formula of EF=(LVDd-LVSd)/ LVDd.

\subsection{Genotyping}

The SNPs for the human MLL3 gene listed in the National Center for Biotechnology Information SNP database (http://www.ncbi.nlm.nih.gov/SNP). We screened data for the Tag SNPs in the International HapMap Project website (http://www.hapmap.org/). We used Haploview 4.2 software (Harvard University, Cambridge, MA, USA) and the HapMap phase II database obtained three tagging SNPs [rs 10244604 (g.152328895A>G), rs6963460 (g.152187985A>G), rs1137721 (g.152301320 C>G, T)] for the Chinese Han subjects using a minor allele frequency (MAF) $\geq 0.05$ and linkage disequilibrium patterns with $r 2 \geq 0.8$ as a cutoff. Genomic DNA was extracted from peripheral blood leukocytes using a DNA extraction kit (Beijing Biotech Co. Ltd. Beijing, China). Genotyping was performed using the TaqMan® SNP Genotyping 
Assay (Applied Biosystems Inc., Foster City, CA, USA) as described previously [19]. Two researchers without the knowledge of case or control status blindly conducted all assays. Additionally, approximately $10 \%$ of the samples were randomly selected and retested, and the results were $100 \%$ concordant.

\subsection{Statistical Analysis}

Quantitative variables with normal distribution were presented as mean \pm SD and analyzed using Student's t-test or ANOVA test, while non-normal distribution was presented as median (interquartile range) and analyzed using Mann-Whitney U-test. Statistical significance was established at $\mathrm{P}<0.05$. Statistical analyses performed using SPSS software for Windows, version 20.0 (SPSS, Chicago, Illinois, USA). The gene interaction model was determined using MDR1.10 according to the standards of the largest crossvalidation consistency coefficient and highest checking sample accuracy.

\subsection{Follow up}

Patients were followed up for a median of 55.7 (47.6-57.9) months. The information was acquired from the records of their inpatients or outpatients or by telephone calls. The endpoint event was all-cause mortality rate death.

\section{Results}

\subsection{Comparison of clinical data}

The differences in clinical data (hypertension, diabetes, smoking, drinking, age, and gender, TC, TG, HDL, WBC, and EF) between Type B AD (158) and the control group (197) were analyzed. As shown in Table 1, significant differences were found $(P<0.05)$, which suggested that clinical factors of smoking, drinking, hypertension, diabetes, age, BMI, TC, TG, SBP, DBP, Scr, WBC, FGB were associated with Type B AD susceptibility.

\subsection{Genotype multiple logistic regression analyses}

Table 2 shows the frequencies of (MLL3, TGFB1, TGFB2, TGFBR1, TGFBR2) alleles and genotypes within seven SNPs in cases and controls. We found that the variants in rs1137721, and rs1800469 were related to increased $A D$ risk after covariant adjustment. $A D$ risks were higher in carriers of the homozygous mutant of rs $1137721 \mathrm{CT} / \mathrm{CC}$ OR $(95 \% \mathrm{Cl})$ was $4.33(1.51-12.40)$, and rs $1800469 \mathrm{AA}+\mathrm{AG} / \mathrm{GG}$ OR $(95 \% \mathrm{Cl})$ was 3.43(1.04-11.30).

\subsection{GMDR analyses}

GMDR model was used to screen the potential best interaction combination among SNPs within MLL3 and TGF- $\beta$. In Table 3, we found that there was a significant gene-gene interaction between rs 1137721 and rs4522809. In this model, the cross-validation consistency is $10 / 10$ and the testing accuracy is $57.19 \%$. Logistic regression indicated that participants with rs $1137721-\mathrm{TT}+\mathrm{CT}$ and rs4522809-AA 
genotype (OR=6.72, 95\% $\mathrm{Cl}=1.56-29.84)$ have the highest Type $B$ AD risk, compared to participants with rs 1137721-CC and rs4522809-AA+GG genotype ( $\mathrm{OR}=4.38,95 \% \mathrm{Cl}=0.92-20.83)$, after covariant adjustment (Table 4). Meanwhile, we also screen the potential best interaction combination among SNPs with the environment (Table 5), we found that there was a significant gene-environment interaction among rs $1137721, \mathrm{TG}$, and TC, In this model, the cross-validation consistency is $10 / 10$ and the training accuracy is $100 \%$.

\section{3 follow up results}

At the end of the study, 16 patients died due to the recurrence of Stanford type $B A D$, and 3 patients expired during hospital days. The association of tag SNPs in patients with type B AD were assessed by the Kaplan-Meier test. Patients with these genotypes were associated with an increased mortality risk: dominant models of rs $1137721 \mathrm{CT} / \mathrm{CC}$, and rs4522809-AA genotype. No statistically significant differences were found between the association of mortality risk and genetic models of rs 1137721 CT/CC, and rs4522809-AA genotype (Figure 1).

\section{Discussion}

In the current study based on the Chinese Han population, we found that variants in MLL3

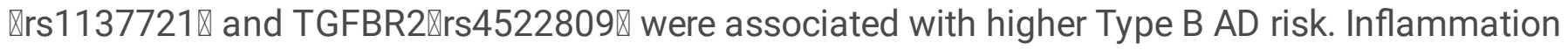
reaction and lipid metabolism were associated with Type $B A D$, such as traditional risk factors smoking, Drinking, Hypertension, Diabetes, SBP, DBP. Meanwhile, HDL-C, LDL-C, WBC, were independent risk factors. Moreover, there exist MLL3-TGF- $\beta$ pathway interactions among these Type B AD.

Based on lipid molecular analysis Study indicate the serum lipid composition that plays a key role in aortic aneurysm formation and AD occurrence ${ }^{[17]}$. Lipid metabolites HDL-C, LDL-C were independent risk factors for Type B AD patients ${ }^{[20]}$. Similar to Our study findings that TG, HDL-C, LDL-C associated with $A D$; multiple logistic regression analysis showed that $L D L-C$ was no statistical significance, but the risk ratio is [OR=1.30(0.90-1.88), $\mathrm{P}=0.16$ ]. The Histone 3 lysine 4 (H3K4) methyltransferases MLL3 regulates lipid metabolic processes including decreased white fat mass, and lipid accumulation in the brown adipose tissue and liver, improved glucose tolerance, increased energy expenditure, and bile acid (BA) levels. ${ }^{[16,17,18,21]}$. MLL3/MLL4 as master enhancer epigenomic writers activated during adipogenesis ${ }^{[22]}$ MLL3(rs1137721 CT) genotype was the highest risk ratios, (OR=4.33, 95\% Cl=1.51-12.40). GMDR showed best the gene-gene interaction models (rs1137721 rs4522809) in affecting Type B AD risk. GMDR showed environment factors TG, TC with MLL3(rs1137721) worked together in affecting Type B AD risk. Clarified that MLL3 gene through by influencing the occurrence of lipid metabolic effects Type B AD development. However, long-term follow-up showed no statistical significance for all-cause mortality.

As identified by increased TGF- $\beta$ signaling contributes to the complicated pathogenesis of aortic aneurysm ${ }^{[15]}$. TGF $\beta 1$ rs 1800469 can affect the TGF- $\beta 1$ plasma levels, located in the promoter region. Rs1800469 is also associated with heart diseases ${ }^{[23]}$. However, genetic associations between rs1800469 
and Debakey III aortic dissection are still confounding. Two studies suggested that rs 1800469 base mutation was associated with the presence of Abdominal Aortic Aneurysms in a UK cohort and Chinese cohort ${ }^{[24,25]}$. However, after adjusting for con-founders this association was lost. Our study logistic regression analysis showed rs1800469 dominant model [OR=3.43(1.04-11.30), $\mathrm{P}=0.04$ ] was an independent risk factor for Type B AD patients.

The GMDR analysis certified that TGFBR2 rs4522809, smoking, dyslipidemia, and MLL3 rs1137721 are likely worked together in affecting Type B AD risk. Transforming growth factor- $\beta$ (TGF- $\beta$ ) signaling pathway associated genes mutations can cause syndromic Thoracic Aortic Dissections (TAAD), such as Marfan syndrome (MFS), Loeys-Dietz syndrome (LDS), and Shprintzen-Goldberg Syndrome (SGS), and these syndromes potentially affect cardiovascular systems ${ }^{[3,4]}$. The cytokine transforming growth factorb type II receptor (TGFBR2) was regulated by Fibrillin-1 ${ }^{[26]}$. In Marfan patients, TGF-b levels are elevated, resulting from increased MMP activity and extracellular matrix breakdown ${ }^{[27]}$. Research in experimental aneurysms has repetitively revealed the activity of the TGF- $\beta$ pathway in Thoracic Aortic Aneurysms [28]. the additional evidence of human mutations in genes encoding effectors of canonical TGF- $\beta$ signaling has led to the hypothesis that aberrant TGF-B signaling drives aneurysm progression ${ }^{[29]}$.

Aortic dissection (AD) has been recognized to be associated with an inflammatory process ${ }^{[30]}$. Chronic inflammation of the adventitia, media, and intima was increased in $A D{ }^{[31]}$. Our study also shows that WBC was associated with AD, logistic regress shows significant results. The GMDR analysis demonstrated that MLL3 rs1137721, drinking, WBC, hypertension, and diabetes mellitus probably worked together in affecting Type $B$ AD risk. These findings showed that WBC, dyslipidemia, and the TGF- $\beta$ pathway might influence Type $B A D$ formation via the vascular fibrotic process, but the specific mechanism is unknown.

There were several limitations worth considering to this study. First, the sample size was small. It was found that the available sample sizes of 158 Type B AD cases and 197 controls had $>60 \%$ and $85 \%$ statistical power to detect ORs of $\sim 1.5$ and $\sim 1.8$ for the association of the risk alleles with Type B AD. Therefore, the results should be requiring a sizable sample to verify. Second, the number of signaling pathway SNPs genotyped was limited. Seven polymorphisms were chosen and one gene-environment interaction affecting Type B AD risk was discovered. Several factors that influenced the presence of Type $B A D$, such as WBC, type 2 diabetes, hypertension, and atherosclerotic diseases, were found to have potential interactions with Type B AD risk; So, a more comprehensive study of complex correlation in Type $B$ AD need to research.

\section{Conclusion}

This study is the first to report that TGFBR2 rs4522809 and MLL3 rs1137721 genetic polymorphisms might be associated with Type B AD risk in the Chinese Han population. Furthermore, complex interactions between environmental factors and polymorphisms might contribute to the risk of Type B AD. 
Owing to the small sample size, the results should be considered preliminary and requiring extensive validation and replication in larger populations.

\section{Declarations}

\section{Funding}

There was no funding support.

\section{Acknowledgments:}

We thank all participants for their enrollment in this study.

\section{Conflicts of interests}

All authors have declared no conflicts of interest.

\section{Contribution of all the authors}

Qinghua Yuan and Yafei Chang contributed to the study design, data collection, experiment implementation, statistical analysis, and manuscript writing and revision. Peipei Jiang and Ling Sun contributed to the data collection and experiment implementation. Xiang Ma and Yitong Ma contributed to the study design, and manuscript revision and approval.

\section{Data Availability Statements}

The data that support the findings of this study are available on request from the corresponding author. The data are not publicly available due to privacy or ethical restrictions.

\section{References}

1. Fletcher AJ, Syed MBJ, Aitman TJ, Newby DE, Walker NL (2020) Inherited Thoracic Aortic Disease: New Insights and Translational Targets. Circulation. 141:1570-1587.

2. Silaschi M, Byrne J, Wendler O (2017) Aortic Dissection: Medical, Interventional and Surgical Management. Heart. 103:78-87.

3. Elefteriades JA, Hatzaras I, Tranquilli MA, Elefteriades AJ, Stout R, Shaw RK, Silverman D, Barash P (2003) Weight lifting and rupture of silent aortic aneurysms. JAMA;290:2803.

4. Hatzaras I, Tranquilli M, Coady M, Barrett PM, Bible J, Elefteriades JA (2007) Weightlifting and aortic dissection: more evidence for a connection. Cardiology; 107:103-106.

5. Dietz HC, Cutting GR, Pyeritz RE, Maslen CL, Sakai LY, Corson GM, Puffenberger EG, Hamosh A, Nanthakumar EJ, Curristin SM (1991) Marfan syndrome caused by a recurrent de novo missense mutation in the fibrillin gene. Nature; 352:337-339. 
6. Neptune ER, Frischmeyer PA, Arking DE, Myers L, Bunton TE, Gayraud B, Ramirez F, Sakai LY, Dietz HC (2003) Dysregulation of TGF-beta activation contributes to pathogenesis in Marfan syndrome. Nat Genet; 33:407-411.

7. He R, Guo DC, Sun W, Papke CL, Duraisamy S, Estrera AL, Safi HJ, Ahn C, Buja LM, Arnett FC, Zhang JW, Geng Y-J, Milewicz DM (2008) Characterization of the inflammatory cells in ascending thoracic aortic aneurysms in patients with Marfan syndrome, familial thoracic aortic aneurysms, and sporadic aneurysms. J Thorac Cardiovasc Surg: 136:922-929.

8. Radonic T, de Witte P, Groenink M, de Waard V, Lutter R, van Eijk M, Jansen M, Timmermans J, Kempers M, Scholte AJ, Hilhorst-Hofstee Y, van den Berg MP, van Tintelen JP, Pals G, Baars MJH, Mulder BJM , Zwinderman AH (2012) Inflammation aggravates disease severity in Marfan syndrome patients. PLoS ONE, 7: e32963.

9. Lindsay ME, Dietz HC (2011) Lessons on the pathogenesis of aneurysm from heritable conditions. Nature; 473:308-316.

10. Gomez D, Coyet A, Ollivier V, Jeunemaitre X, Jondeau G, Michel J-B, Vranckx R (2011) Epigenetic control of vascular smooth muscle cells in Marfan and non-Marfan thoracic aortic aneurysms. Cardiovasc Res; 89:446-456.

11. Lakshmi SP, Reddy AT, Reddy RC (2017) Transforming Growth Factor $\beta$ Suppresses Peroxisome Proliferator-Activated Receptor $\gamma$ Expression via Both SMAD Binding and Novel TGF- $\beta$ Inhibitory Elements. Biochem J. 474:1531-1546.

12. Pannu H, Fadulu VT, Chang J, Lafont A, Hasham SN, Sparks E, Giampietro PF, Zaleski C, Estrera AL, Safi HJ, Shete S, Willing MC, Raman CS, Milewicz DM (2005) Mutations in transforming growth factor-beta receptor type II cause familial thoracic aortic aneurysms and dissections. Circulation. 112:513-520.

13. Lerner-Ellis JP, Aldubayan SH, Hernandez AL, Kelly MA, Stuenkel AJ, Walsh J, Joshi VA (2014) The spectrum of FBN1, TGFBR1, TGFBR2 and ACTA2 variants in 594 individuals with suspected Marfan Syndrome, Loeys-Dietz Syndrome or Thoracic Aortic Aneurysms and Dissections (TAAD). Mol Genet Metab. 112:171-176.

14. Leutermann R, Sheikhzadeh S, Brockstädt L, Rybczynski M, van Rahden V, Kutsche K, von Kodolitsch Y, Rosenberger G (2014) A 1-bp Duplication in TGFB2 in Three Family Members With a Syndromic Form of Thoracic Aortic Aneurysm. Eur J Hum Genet. 22:944-948.

15. Takeda N, Hara H, Fujiwara T, Kanaya T, Maemura S, Komuro I (2018) TGF- $\beta$ Signaling-Related Genes and Thoracic Aortic Aneurysms and Dissections. Int J Mol Sci. 19:2125.

16. Kim DH, Lee J, Lee B, Lee JW (2009) ASCOM controls farnesoid X recepor transactivation through its associated histone $\mathrm{H} 3$ lysine 4 methyltransferase activity. Mol Endocrinol; 23:1556-1562.

17. Lee J, Saha PK, Yang QH, Lee S, Park JY, Suh Y, Lee SK, Chan L, Roeder RG, \& Lee JW (2008) Targeted inactivation of MLL3 histone H3-Lys-4 methyltransferase activity in the mouse reveals vital roles for MLL3 in adipogenesis. Proc Natl Acad Sci U S A;105: 19229-19234. 
18. Kim DH, Kim J, Lee JW (2011) Requirement for MLL3 in p53 regulation of hepatic expression of small heterodimer partner and bile acid homeostasis. Mol Endocrinol;25: 2076-2083.

19. Yuan Q, Xie X, Fu Z, Ma X, Yang Y, Huang D, Liu F, Dai C, Ma Y (2014) Association of the histonelysine N-methyltransferase MLL5 gene with coronary artery disease in Chinese Han people. Meta Gene. 2:514-524.

20. Harrison SC, Holmes MV, Burgess S, Asselbergs FW, Jones GT, Baas AF, van 't Hof FN, de Bakker P, Blankensteijn JD, Powell JT, Saratzis A, de Borst GJ, Swerdlow DI, van der Graaf Y, van Rij AM, Carey DJ, Elmore JR, Tromp G, Kuivaniemi H, Sayers RD, Samani NJ, Bown MJ, Humphries SE (2018) Genetic Association of Lipids and Lipid Drug Targets With Abdominal Aortic Aneurysm: A Metaanalysis. JAMA Cardiol 3:26-33.

21. Lee S, Lee J, Lee SK, Lee JW (2008) Activating signal cointegrator-2 is an essential adaptor to recruit histone H3 lysine 4 methyltransferases MLL3 and MLL4 to the liver X receptors. Mol Endocrinol; 22:1312-1319.

22. Lai BB, Lee JE, Jang YH, Wang LF, Peng WQ, Ge K (2017) MLL3/MLL4 Are Required for CBP/p300 Binding on Enhancers and Super-Enhancer Formation in Brown Adipogenesis. Nucleic Acids Res. 45:6388-6403.

23. Lu Y, Boer JM, Barsova RM, Favorova O, Goel A, Muller M, Feskens EJ (2012) TGFB1 genetic polymorphisms and coronary heart disease risk: a meta-analysis. BMC Med Genet; 13:39.

24. Thompson AR, Cooper JA, Jones GT, Drenos F, van Bockxmeer FM, Biros E, Walker PJ, van Rij AM, Golledge J, Norman PE, Hafez H, Humphries SE (2010) Assessment of the association between genetic polymorphisms in transforming growth factor beta, and its binding protein (LTBP), and the presence, and expansion, of abdominal aortic aneurysm. Atherosclerosis 209:367-373.

25. Zuo S, Xiong J, Chen F, Guo W, Wei Y, Chen D, Liu K, Wu T, Hu Y (2015) Potential Interactions Between Genetic Polymorphisms of the Transforming Growth Factor- $\beta$ Pathway and Environmental Factors in Abdominal Aortic Aneurysms. European Journal of Vascular and Endovascular Surgery, 50:71-77.

26. Dietz HC, Cutting GR, Pyeritz RE, Maslen CL, Sakai LY, Corson GM, Puffenberger EG, Hamosh A, Nanthakumar EJ, Curristin SM (1991) Marfan syndrome caused by a recurrent de novo missense mutation in the fibrillin gene. Nature; 352:337-339.

27. Goldfinger JZ, Halperin JL, Marin ML, Stewart yAS, Eagle KA, Fuster xV (2014) Thoracic Aortic Aneurysm and Dissection.Journal of the American College of Cardiology. 64:1725-1739.

28. Saratzis A, Bown MJ (2014) The genetic basis for aortic aneurysmal disease. Heart. 100:916-922.

29. Isselbacher EM, Lino Cardenas CL, Lindsay M E (2016) Hereditary Influence in Thoracic Aortic Aneurysm and Dissection. Circulation. 133:2516-2528.

30. Xu H, Du S, Fang B, Li C, Jia X, Zheng S, Wang S, Li Q, Su W, Wang N, Zheng F, Chen L, Zhang X, Gustafsson JÅ, Guan Y (2019) VSMC-specific EP4 deletion exacerbates angiotensin Il-induced aortic dissection by increasing vascular inflammation and blood pressure. Proc Natl Acad Sci U S A. 116:8457-8462. 
31. Niinimäk E, Pynnönen V, Kholova I, Paavonen T, Mennander A (2018) Neovascularization With Chronic Inflammation Characterizes Ascending Aortic Dissection. Anatol J Cardiol. 20:289-295.

\section{Tables}

Table 1 Basic Characteristic of Participants Stratified According to with or without type B aortic dissection

\begin{tabular}{|llll|}
\hline Variables & $\begin{array}{l}\text { Controls } \\
(\mathrm{n}=197)\end{array}$ & $\begin{array}{l}\text { AD cases } \\
(\mathrm{n}=158)\end{array}$ & $\mathrm{P}$ \\
\hline Gender $(\mathrm{male})$ & $157(44.2)$ & $133(37.5)$ & 0.33 \\
\hline Age (year) & $55.87 \pm 11.43$ & $51.18 \pm 12.01$ & $<0.01$ \\
\hline BMI $\left(\mathrm{kg} / \mathrm{m}^{2}\right)$ & $25.84 \pm 3.08$ & $27.10 \pm 7.26$ & 0.04 \\
\hline Smoking $(\%)$ & $63(17.8)$ & $94(26.6)$ & $<0.01$ \\
\hline Drinking $(\%)$ & $45(12.7)$ & $90(25.5)$ & $<0.01$ \\
\hline Hypertension $(\%)$ & $83(23.4)$ & $123(34.7)$ & $<0.01$ \\
\hline Diabetes $(\%)$ & $21(6)$ & $10(2.9)$ & 0.14 \\
\hline SBP(mmHg) & $126.69 \pm 16.63$ & $151.30 \pm 29.75$ & $<0.01$ \\
\hline DBP(mmHg) & $80.17 \pm 32.11$ & $87.05 \pm 18.80$ & 0.01 \\
\hline Scr $($ ummo/l) & $74.34 \pm 16.79$ & $94.16 \pm 100.76$ & $<0.01$ \\
\hline TC(mmol/l) & $4.19 \pm 1.12$ & $4.43 \pm 2.37$ & 0.20 \\
\hline TG(mmol/l) & $1.73 \pm 0.99$ & $2.60 \pm 4.82$ & 0.01 \\
\hline HDL-C(mmol/l) & $1.10 \pm 0.32$ & $2.05 \pm 5.01$ & $<0.01$ \\
\hline LDL-C(mmol/l) & $2.67 \pm 1.18$ & $5.63 \pm 13.56$ & $<0.01$ \\
\hline WBC(10 $/ /)$ & $6.68 \pm 1.98$ & $11.52 \pm 4.10$ & $<0.01$ \\
\hline FGB(mmol/l) & $5.46 \pm 1.85$ & $10.79 \pm 31.31$ & 0.02 \\
\hline
\end{tabular}

Table 2a Genotype and allele distributions in patients with Debakey III AD and control subjects. 


\begin{tabular}{|c|c|c|c|c|c|}
\hline \multirow[t]{2}{*}{ SNPs } & \multirow[t]{2}{*}{ Genotypes and Alleles } & \multicolumn{2}{|c|}{ Frequencies N (\%) } & \multirow[t]{2}{*}{$\mathrm{OR}(95 \% \mathrm{Cl})$} & \multirow[t]{2}{*}{$P$} \\
\hline & & Cases $₫ 158 \rrbracket$ & Controls $₫ 197 \rrbracket$ & & \\
\hline \multicolumn{6}{|l|}{ MLL3 } \\
\hline \multirow[t]{6}{*}{ rs10244604 } & $\mathrm{AA}$ & $117(34.5)$ & $159(46.9)$ & 1.0 & \\
\hline & $A G$ & $26(7.7)$ & $33(9.7)$ & $1.13(0.44-2.94)$ & 0.80 \\
\hline & GG & $2(0.6)$ & $2(0.6)$ & $0.64(0.04-10.6)$ & 0.76 \\
\hline & $A A+A G / G G$ & $143(42.2)$ & 192(56.6) & $1.59(0.1-26.1)$ & 0.75 \\
\hline & $A$ & $260(38.3)$ & $351(51.8)$ & & \\
\hline & G & $30(4.4)$ & $37(5.5)$ & & \\
\hline \multirow[t]{6}{*}{ rs6963460 } & AA & $92(28.0)$ & 128(39.0) & 1.0 & \\
\hline & $A G$ & $40(12.2)$ & $52(15.9)$ & $1.11(0.4-2.7)$ & 0.83 \\
\hline & GG & $5(1.5)$ & $11(3.4)$ & $1.07(0.17-6.73)$ & 0.94 \\
\hline & $A A+A G / G G$ & $132(40.2)$ & $180(54.9)$ & $0.96(0.16-5.89)$ & 0.97 \\
\hline & A & $224(34.1)$ & $308(47.0)$ & & \\
\hline & G & $50(7.6)$ & 74(11.3) & & \\
\hline \multirow[t]{6}{*}{ rs1137721 } & $\mathrm{CC}$ & $46(13.8)$ & $75(22.5)$ & 1.0 & \\
\hline & $\mathrm{CT}$ & $81(24.3)$ & $90(26.9)$ & $4.33(1.51-12.40)$ & $<0.01$ \\
\hline & $\mathrm{TT}$ & $15(4.5)$ & $27(8.1)$ & $2.19(0.45-10.65)$ & 0.33 \\
\hline & $\mathrm{CC}+\mathrm{CT} / \mathrm{TT}$ & $127(38.0)$ & $165(49.4)$ & $1.18(0.30-4.63)$ & 0.81 \\
\hline & C & $173(25.9)$ & $240(35.9)$ & & \\
\hline & $\mathrm{T}$ & $111(16.6)$ & $144(21.6)$ & & \\
\hline
\end{tabular}

Table 2b Genotype and allele distributions in patients with Debakey III AD and control subjects. 


\begin{tabular}{|c|c|c|c|c|c|}
\hline \multirow[t]{2}{*}{ SNPs } & \multirow{2}{*}{$\begin{array}{l}\text { Genotypes } \\
\text { and Alleles }\end{array}$} & \multicolumn{2}{|c|}{ Frequencies N (\%) } & \multirow[t]{2}{*}{$\mathrm{OR}(95 \% \mathrm{Cl})$} & \multirow[t]{2}{*}{$\mathrm{P}$} \\
\hline & & cases & controls & & \\
\hline \multicolumn{6}{|l|}{ TGFBR1 } \\
\hline \multirow[t]{6}{*}{ rs1626340 } & $\mathrm{AA}$ & $22(6.9)$ & $36(11.3)$ & 1.0 & \\
\hline & $A G$ & $70(22.0)$ & $67(21.1)$ & $2.91(0.97-8.73)$ & 0.06 \\
\hline & GG & $53(16.7)$ & $70(22.0)$ & $0.67(0.20-2.25)$ & 0.52 \\
\hline & $A A+A G / G G$ & $123(38.7)$ & $137(43.1)$ & $1.59(0.59-4.29)$ & 0.36 \\
\hline & $A$ & $114(17.9)$ & $139(21.9)$ & & \\
\hline & G & $176(27.7)$ & $207(32.5)$ & & \\
\hline \multicolumn{6}{|l|}{ TGFBR2 } \\
\hline \multirow[t]{6}{*}{ rs4522809 } & AA & $67(19.7)$ & $102(30.0)$ & 1.0 & \\
\hline & $A G$ & $71(20.9)$ & $80(23.5)$ & $1.34(0.56-3.22)$ & 0.51 \\
\hline & GG & $8(2.4)$ & $12(3.5)$ & $0.66(0.11-3.85)$ & 0.65 \\
\hline & $A A+A G / G G$ & $138(40.6)$ & $182(53.5)$ & $1.75(0.32-9.58)$ & 0.52 \\
\hline & $A$ & $205(30.1)$ & $284(41.8)$ & & \\
\hline & G & $87(12.8)$ & 104(15.3) & & \\
\hline \multicolumn{6}{|l|}{ TGFB1 } \\
\hline \multirow[t]{6}{*}{ rs1800469 } & $\mathrm{AA}$ & $35(10.9)$ & $49(15.2)$ & 1.0 & \\
\hline & $A G$ & $65(20.2)$ & $95(29.5)$ & $1.15(0.41-3.22)$ & 0.78 \\
\hline & GG & $29(9.0)$ & $49(15.2)$ & $0.33(0.08-1.34)$ & 0.12 \\
\hline & $A A+A G / G G$ & 100(31.1) & $144(44.7)$ & $3.43(1.04-11.30)$ & 0.04 \\
\hline & $A$ & 135(21.0) & 193(30.0) & & \\
\hline & G & 123(19.1) & 193(30.0) & & \\
\hline \multicolumn{6}{|l|}{ TGFB2 } \\
\hline \multirow[t]{5}{*}{ rs900 } & AA & 10囚2.9凶 & $9 \rrbracket 2.7 \rrbracket$ & 1.0 & \\
\hline & AT & $64 \rrbracket 18.9 \rrbracket$ & 81®23.9凶 & $0.67(0.13-3.45)$ & 0.62 \\
\hline & TT & $71(20.9)$ & 104(30.7) & $0.59(0.11-3.14)$ & 0.54 \\
\hline & $\mathrm{AA}+\mathrm{AT} / \mathrm{TT}$ & $74(21.8)$ & $90(26.5)$ & $1.16(0.52-2.60)$ & 0.70 \\
\hline & $A$ & $84(12.4)$ & $99(14.6)$ & & \\
\hline
\end{tabular}


$\begin{array}{lll}T & \text { 206(30.4) 289(42.6) }\end{array}$

Adjustment for age, alcohol consumption, smoking, SBP, DBP, Scr, FBG, TG, HDL-C, LDL-C, DM, HP, BMI and WBC.

Table 3: Best gene-gene interaction models, as identified by GMDR

\begin{tabular}{|llllll|}
\hline $\begin{array}{l}\text { Locus } \\
\text { no }\end{array}$ & Best combination & $\begin{array}{l}\text { Cross- } \\
\text { validation } \\
\text { consistency }\end{array}$ & $\begin{array}{l}\text { Testing } \\
\text { accuracy }\end{array}$ & $\begin{array}{l}p^{-} \\
\text {values* }\end{array}$ & $\begin{array}{l}\text { CV } \\
\text { consistency }\end{array}$ \\
\hline 2 & rs1137721 & 0.5531 & 0.4532 & 0.9893 & $4 / 10$ \\
\hline 3 & rs1137721 rs4522809 & 0.5864 & 0.5759 & 0.0010 & $10 / 10$ \\
\hline 4 & rs6963460rs1822825rs1800469 & 0.6305 & 0.4855 & 0.9453 & $6 / 10$ \\
\hline
\end{tabular}

Table 4: Interaction between rs1137721 and rs4522809 on type B AD risk

\begin{tabular}{|llll|}
\hline rs 1137721 & rs4522809 & OR $(95 \% \mathrm{Cl})$ & p-values a \\
\hline CC & AA & 1.0 & \\
\hline TT+CT & AG+GG & $6.27(1.42-27.75)$ & 0.016 \\
\hline CC & AG+GG & $4.38(0.92-20.83)$ & 0.064 \\
TT+CT & AA & $6.72(1.56-28.94)$ & 0.010 \\
\hline
\end{tabular}

Table 5: Best gene-environment interaction models, as identified by GMDR

\begin{tabular}{|lllll|}
\hline Best combination & Training Bal.Acc & $\begin{array}{l}\text { Testing } \\
\text { Bal.Acc }\end{array}$ & p-values* & CV consistency \\
\hline TC & 0.9051 & 0.6768 & 0.0010 & $10 / 10$ \\
\hline TG LDL & 0.9977 & $\mathrm{NaN}$ & 0.0010 & $6 / 10$ \\
\hline rs1137721 TG TC & 1.0000 & $\mathrm{NaN}$ & 0.0010 & $10 / 10$ \\
\hline
\end{tabular}

Figures 


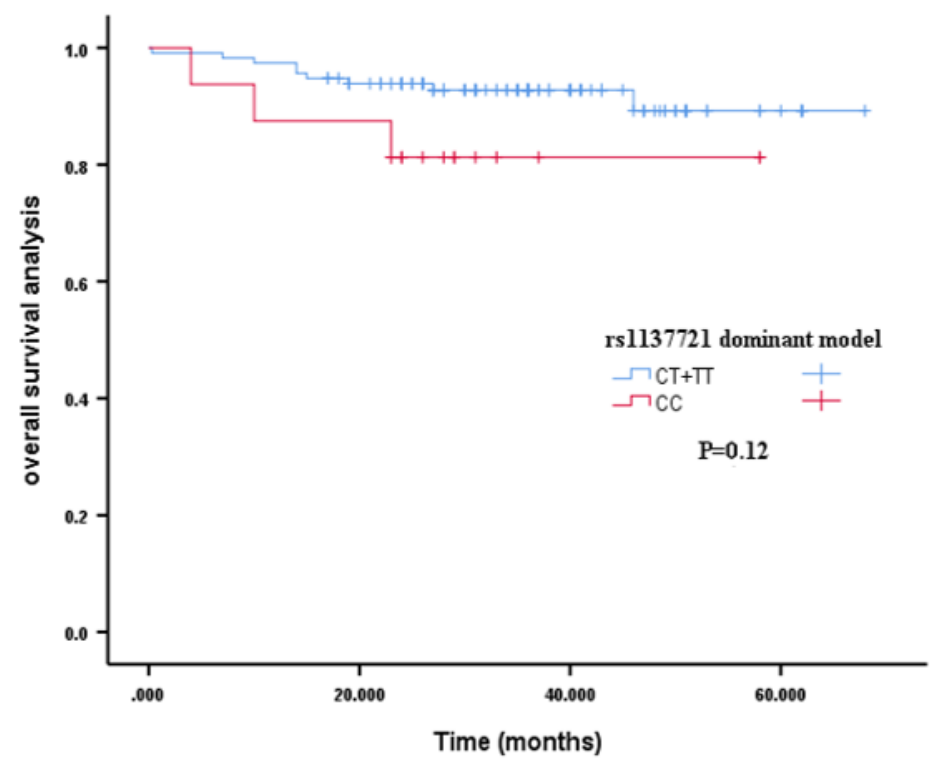

A

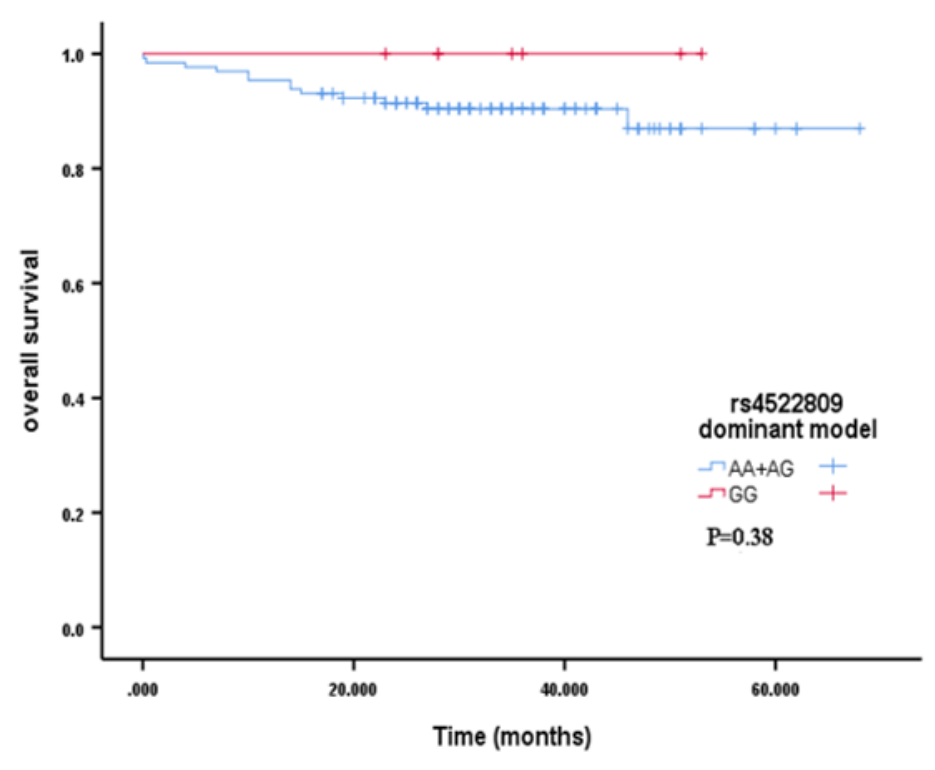

B

Figure 1

A: Kaplan-Meier analysis of the overall survival based on MLL3 rs1137721 dominant model; B: KaplanMeier analysis of the overall survival based on TGFR2 rs4522809 dominant model; 